\title{
Xanthogranuloma of the intrasellar region presenting in pituitary dysfunction: a case report
}

\author{
Takamasa Nishiuchi ${ }^{1}, K_{0 j i}$ Murao ${ }^{1 *}$, Hitomi Imachi ${ }^{1}$, Yoshio Kushida² ${ }^{2}$ Reiji Haba², Nobuyuki Kawai ${ }^{3}$, Takashi Tamiya ${ }^{3}$ \\ and Toshihiko Ishida'
}

\begin{abstract}
Introduction: Differentiation of cystic mass lesions of the sellar and parasellar regions may pose a diagnostic dilemma for physicians, neurosurgeons, radiologists and pathologists involved in treating patients with these entities. A considerable number of tumors previously identified as craniopharyngiomas may, in fact, have been xanthogranulomas. We report a case of pituitary dysfunction caused by xanthogranuloma of the intrasellar region.

Case presentation: A 47-year-old man of Japanese descent presented to our institution with a tumor located exclusively in the intrasellar region which manifested as severe hypopituitarism. MRI revealed a clearly defined intrasellar mass that was heterogeneously hyperintense on T1-weighted images and markedly hypointense on T2weighted images. We preoperatively diagnosed the patient with Rathke's cleft cyst or non-functioning pituitary adenoma. Although the tumor was completely removed using a transsphenoidal approach, the improvement of the patient's endocrine function was marginal, and continued endocrine replacement therapy was needed. Postoperatively, a histological examination revealed the tumor to be a xanthogranuloma of the intrasellar region. His visual field defects and headache improved.
\end{abstract}

Conclusion: Because diagnosis depends on surgical intervention and xanthogranulomas of the intrasellar region are very rare, the natural history of xanthogranuloma is still unknown. Therefore, this entity is difficult to diagnose preoperatively. We suggest that xanthogranuloma should be included in the differential diagnosis, even in the case of sellar lesions, to formulate appropriate postoperative management and improve endocrine outcomes.

Keywords: xanthogranuloma, intrasellar region, craniopharyngioma, Rathke's cleft cyst, panhypopituitarism

\section{Introduction}

Intracranial xanthogranulomas arise most commonly in the choroid plexus, almost uniformly in the trigone of the lateral ventricle, whereas xanthogranulomas of the sellar region are quite rare [1]. In some cases, a significant degree of overlap in these features occurs, and many xanthogranulomas of the sellar region may have been incorrectly identified as craniopharyngiomas. One study found that 37 craniopharyngiomas (33.6\%) consisted predominantly of a xanthogranulomatous component [2]. Xanthogranulomas, also known as cholesterol granulomas, are granulomatous lesions characterized by cholesterol clefts, hemosiderin deposits, multi-nucleated foreign body

\footnotetext{
* Correspondence: mkoji@kms.ac.jp

'Division of Hematology, Endocrinology and Metabolism, Department of Internal Medicine, Faculty of Medicine, Kagawa University, 1750-1, Miki-cho, Kita-gun, Kagawa, 761-0793, Japan

Full list of author information is available at the end of the article
}

giant cells, foamy macrophage accumulation and fibrous proliferation [2-6]. It is not clear, however, whether these additional characteristics represent a distinct entity, given the greater number of characteristics that xanthogranulomas share with craniopharyngiomas. Because the diagnosis depends on surgical intervention, the natural history of xanthogranulomas is unknown. Therefore, it is difficult to diagnose them preoperatively. Furthermore, when xanthogranuloma components predominate in the lesion, differential diagnosis of various lesions with xanthogranuloma is difficult $[7,8]$. Additionally, no typical radiological signs exist for xanthogranulomas [9]. Differentiation of cystic mass lesions of the sellar and parasellar regions may pose a diagnostic dilemma for neurosurgeons, radiologists and pathologists involved in treating patients with these entities. Establishing an accurate working diagnosis for sellar region pathology or histology is critical in predicting the

\section{(Ciomed Central}


likelihood of lesion recurrence and guiding postoperative adjunctive management. Therefore, further reports are required so that clinicians can gain greater insight into the clinical course, management and associated outcome of xanthogranuloma. Herein we report the case of a patient with pituitary dysfunction caused by xanthogranuloma of the intrasellar region.

\section{Case presentation}

A 47-year-old man of Japanese origin presented with a history of headache, general fatigue and appetite loss of 3 months' duration. He was $178.2 \mathrm{~cm}$ in height and weighed $57 \mathrm{~kg}$. His blood pressure was $90 / 50 \mathrm{mmHg}$, and his pulse was 64 beats/minute. His clinical examination showed the patient to be alert with initial signs of uppervisual-field defects. His physical examination revealed no absence of axillary or pubic hair and no neurological abnormalities. The results of the initial laboratory examinations conducted to determine hormone status are presented in Table 1. The anterior pituitary provocation test

Table 1 Laboratory data of the patient ${ }^{a}$

\begin{tabular}{|c|c|c|}
\hline Parameter & Laboratory data & Normal range \\
\hline ACTH $(p g / m l)$ & 5 & 4 to 48 \\
\hline Prolactin (ng/ml) & 1.0 & 0 to 10 \\
\hline $\mathrm{GH}(\mathrm{ng} / \mathrm{ml})$ & 0.3 & 0 to 5 \\
\hline IGF-I (ng/ml) & 30 & 264 to 542 \\
\hline $\mathrm{TSH}(\mu \mathrm{IU} / \mathrm{ml})$ & 2.013 & 0.3 to 5.0 \\
\hline $\mathrm{ADH}(\mathrm{pg} / \mathrm{ml})$ & 0.3 & 0.3 to 4.2 \\
\hline $\mathrm{LH}(\mathrm{mlU} / \mathrm{ml})$ & 0.9 & $>0.5$ \\
\hline FSH (mlU/ml) & 2.7 & $>1.0$ \\
\hline Testosterone (ng/dl) & $<70$ & 330 to 740 \\
\hline Cortisol ( $\mu \mathrm{g} / \mathrm{dl})$ & 2.2 & 5 to 17.9 \\
\hline $\mathrm{F}-\mathrm{T} 4(\mathrm{ng} / \mathrm{dl})$ & 0.56 & 0.97 to 1.69 \\
\hline White blood cells (cells/ $\mu$ l) & 5700 & 4700 to 8700 \\
\hline Red blood cells $\left(\times 10^{4} / \mu \mathrm{l}\right)$ & 375 & 400 to 540 \\
\hline Hemoglobin (g/dl) & 11.1 & 13 to 17 \\
\hline $\mathrm{LDH}(\mathrm{U} / \mathrm{l})$ & 236 & 90 to 280 \\
\hline GOT (U/l) & 65 & 8 to 40 \\
\hline GPT (U/L) & 81 & 4 to 40 \\
\hline $\mathrm{Na}^{+}(\mathrm{mEq} / \mathrm{L})$ & 142 & 135 to 145 \\
\hline $\mathrm{K}^{+}(\mathrm{mEq} / \mathrm{L})$ & 4.4 & 3.5 to 5.0 \\
\hline $\mathrm{Cl}(\mathrm{mEq} / \mathrm{L})$ & 103 & 98 to 108 \\
\hline $\mathrm{Ca}^{2+}(\mathrm{mg} / \mathrm{dl})$ & 8.4 & 8.5 to 10.0 \\
\hline Glucose (mg/dl) & 74 & 65 to 110 \\
\hline Plasma osmolality (mOsm/kg $\mathrm{H}_{2} \mathrm{O}$ ) & 287 & 284 to 294 \\
\hline Urine osmolality $\left(\mathrm{mOsm} / \mathrm{kg} \mathrm{H}_{2} \mathrm{O}\right)$ & 446 & 200 to 900 \\
\hline Urine 17-OHCS (mg/day) & 0.6 & 3 to 9 \\
\hline Urine 17-KS (mg/day) & 3.5 & 3 to 11 \\
\hline
\end{tabular}

aLaboratory data are from initial evaluation. ACTH, adrenocorticotropin; $\mathrm{GH}$, growth hormone; IGF-I, insulin-like growth factor I; TSH, thyroid-stimulating hormone; $\mathrm{ADH}_{\text {, }} \mathrm{LH}$, luteinizing hormone; $\mathrm{FSH}$, follicle-stimulating hormone; $\mathrm{F}$ T4, free thyroxine; LDH, lactate dehydrogenase; GOT, glutamic oxaloacetic transaminase; GPT, glutamic pyruvic transaminase; 17-OHCS, 17hyroxycorticosteroid; 17-KS, 17-ketosteroid. with corticotropin-releasing hormone, growth hormonereleasing hormone, gonadotropin-releasing hormone and thyrotropin-releasing hormone revealed impairment or low response of the secretory functions of cortisol, adrenocorticotropin, growth hormone, follicle-stimulating hormone, luteinizing hormone, thyroid-stimulating hormone and prolactin (Table 2). These abnormal responses to hormone stimulation, along with the patient's hormonal status, were indicative of hypopituitarism, specifically, hypogonadotropic hypogonadism.

MRI showed a clearly defined, intra- and suprasellar lesions with a diameter of $12 \times 18 \times 15 \mathrm{~mm}$. The lesion appeared as mainly isointense to gray matter with some hyperintense areas and showed inhomogeneous contrast enhancement in the T1-weighted images (Figures 1A and $1 \mathrm{~B}$ ). The mass was also heterogeneously iso- or hypointense on T2-weighted images (Figure 1C).

On the basis of the above-mentioned examinations, our preoperative diagnosis was Rathke's cleft cyst (RCC) or non-functioning pituitary adenoma associated with hypophysitis. The lesion was completely removed by surgical exploration via transsphenoidal selective tumorectomy 5 months after clinical onset. Our pathological examination of the pituitary tumor revealed that the tumor was composed of abundant small epithelial cells with foamy macrophage or lymphoid infiltration, some of which were undergoing necrosis (Figure 2A). Hemosiderin deposits were also observed (Figure 2B). Atypically, there was no evidence of calcification or remarkable cholesterol clefts. On the basis of the histopathological examination, we confirmed the presence of an intrasellar xanthogranuloma and no observed cholesterol clefts.

Postoperatively, the patient's visual field defects and headache improved. However, he needed to continue endocrine replacement therapy $(20 \mathrm{mg} /$ day of hydrocortisone and 25 to $50 \mu \mathrm{g} /$ day of thyroxine). MRI showed that

Table 2 Results of the anterior pituitary provocation test; adrenocorticotropic hormone and cortisol response for corticotropin-releasing hormone stimulation, growth hormone response for growth hormone-releasing hormone stimulation, luteinizing hormone and folliclestimulating hormone response for gonadotropinreleasing hormone stimulation ${ }^{\text {a }}$

\begin{tabular}{lllll}
\hline Parameter & $\mathbf{0}$ minutes & $\mathbf{3 0}$ minutes & $\mathbf{6 0}$ minutes & $\mathbf{9 0}$ minutes \\
\hline TSH $(\mu \mathrm{lU} / \mathrm{ml})$ & 2.592 & 5.357 & 5.206 & 4.564 \\
PRL $(\mathrm{ng} / \mathrm{ml})$ & 1 & 1 & 1 & 1 \\
ACTH $(\mathrm{pg} / \mathrm{ml})$ & 12 & 17 & 21 & 18 \\
Cortisol $(\mu \mathrm{g} / \mathrm{dl})$ & 4.7 & 6.3 & 8 & 5.4 \\
$\mathrm{GH}(\mathrm{ng} / \mathrm{ml})$ & 0.1 & 1 & 1.2 & 0.9 \\
$\mathrm{LH}(\mathrm{m} / \mathrm{U} / \mathrm{L})$ & 0.9 & 3 & 3.4 & 3.2 \\
$\mathrm{FSH}(\mathrm{mlU} / \mathrm{L})$ & 2.7 & 2.9 & 3.1 & 3.6
\end{tabular}

${ }^{\mathrm{a}} \mathrm{TSH}$ : thyroid-stimulating hormone, PRL: prolactin, $\mathrm{ACTH}$ : adrenocorticotropic hormone, GH: growth hormone, LH: luteinizing hormone, FSH: folliclestimulating hormone. 


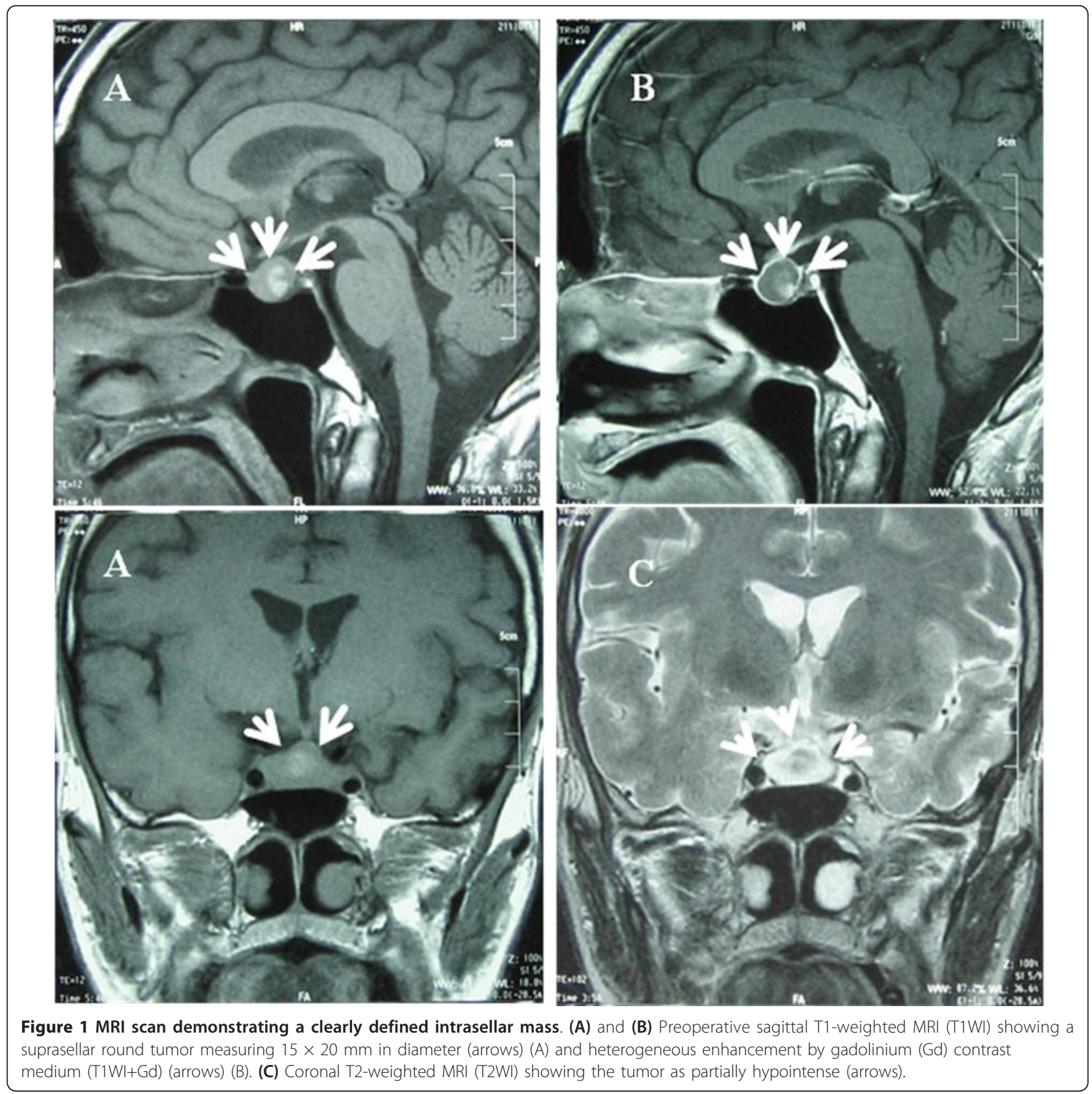

the mass had been completely removed and revealed no evidence of tumor remnants.

\section{Discussion}

The spectrum of cystic pathology occurring in the sellar region includes craniopharyngiomas, RCCs, colloid cysts, arachnoid cysts, cystic pituitary adenomas, epidermoid cysts, dermoid cysts and xanthogranulomas $[10,11]$. Xanthogranulomas have been reported to occur at various sites inside and outside the cranial vault [2]. However, xanthogranuloma of the sellar region is very rare. Xanthogranuloma of the sellar region was first reported in 1988 [3], with only 4 of 211 sellar and juxtasellar tumors $(1.9 \%)$ showing the features typical of cholesterol granulomas. Paulus et al. described and classified xanthogranuloma of the sellar region as a distinct entity, after which the World Health Organization accepted that xanthogranuloma of the sellar region differs from classical craniopharyngioma in several ways: age at onset, anatomical site and localization of the lesion, and symptoms and prognosis $[2,12]$.

The histogenesis and pathogenesis of xanthogranuloma remain unclear, and these details are controversial and probably heterogeneous. It is generally thought that 
A.

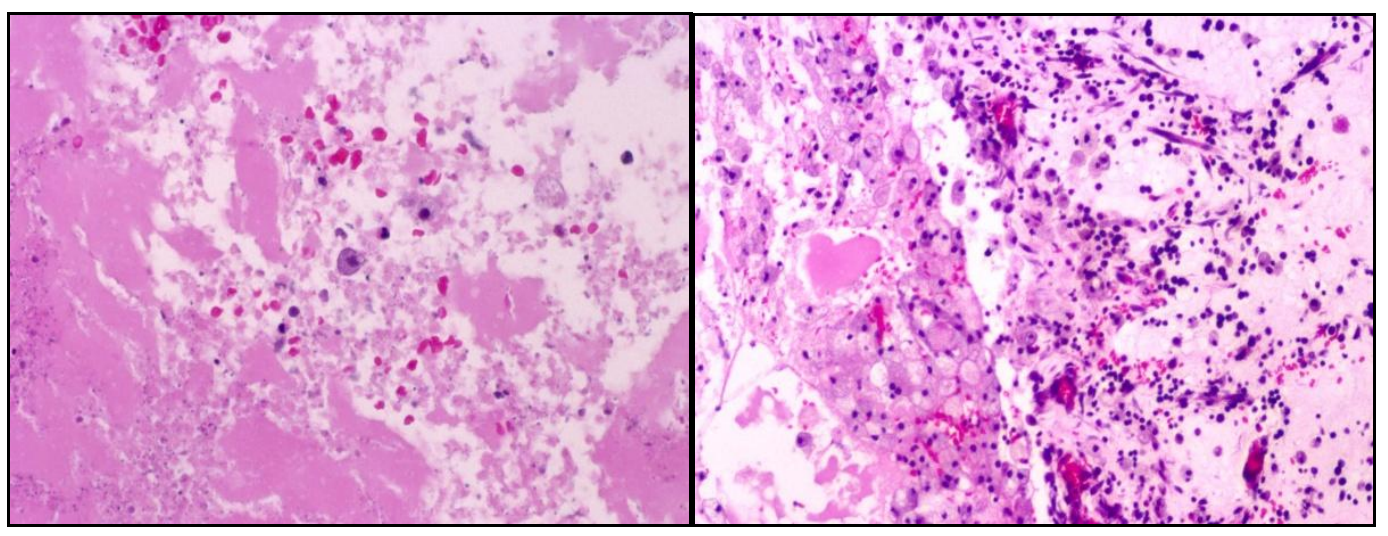

B.

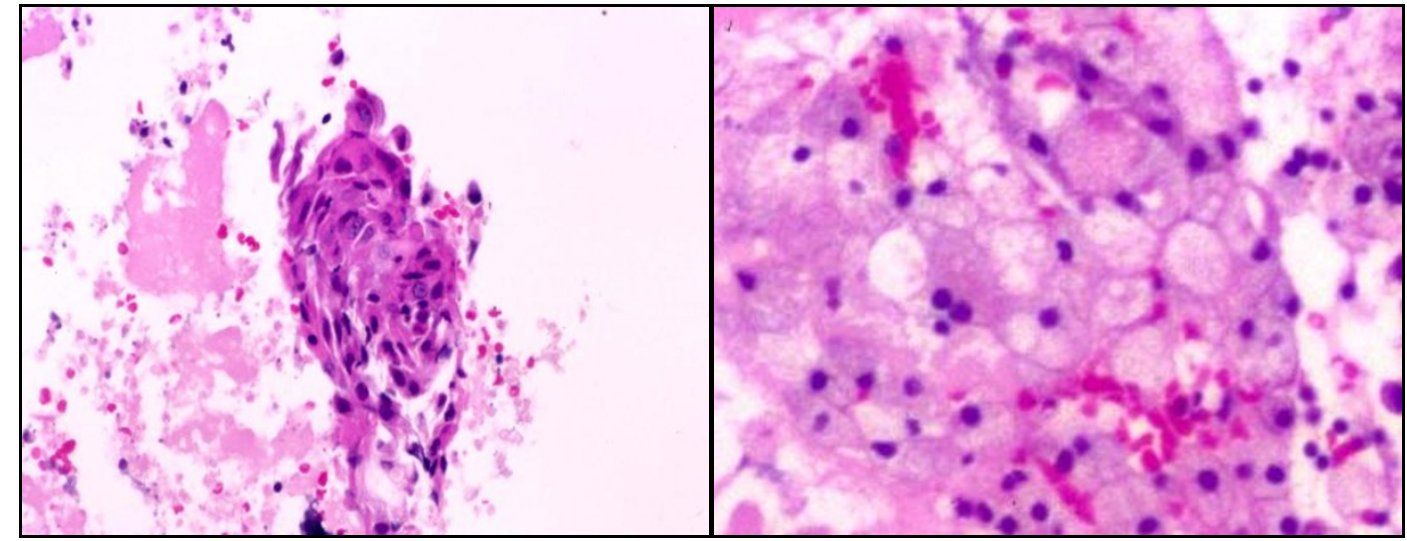

Figure 2 Photomicrographs of the resected tumor showing that the tumor consisted of lymphoid or foamy macrophage infiltration (A) and (B) with small clusters of epithelial cells. (A) Original magnification, $\times 200$ (hematoxylin and eosin stain (H \& E)). (B) Original magnification, $\times 400(H$ \& E).

the xanthogranulomatous reaction is induced mainly by chronic inflammatory processes in circumscribed areas of craniopharyngiomas or at the cyst wall and adjacent tissue of RCCs $[2,13]$. Degenerative changes in pituitary adenomas also may act as triggers [3], and extreme adeno- or infundibuloneurohypophysitis may result in giant cell granuloma. Secondary hypophysitis can arise from bacterial, viral and fungal infections, often in an immunocompromised host, or from systemic disorders such as autoimmune diseases, Langerhans histiocytosis and Erdheim-Chester disease. On the other hand, Paulus et al. [2] proposed xanthogranuloma of the sellar region as a distinct entity and found hemosiderin deposits in almost all (97\%) of their 37 cases as a result of obstruction of a cavity, hemorrhage or both. Compared to classical craniopharyngiomas, xanthogranulomas characteristically occur in adolescents and young adults, predominantly at an intrasellar location, and are smaller in size and concomitant with more severe endocrine deficiencies, but they are more easily resected and lead to good treatment outcomes. Craniopharyngiomas usually arise in the pituitary stalk and grow, at least during the initial stage, mainly in the suprasellar space. The tumor in our patient was found at a classical location for RCCs, pituitary adenomas or hypophysitis, that is, the intrasellar portion and the sella turcica $[2,5,6,9]$, although the adenomatous lesion was not included histologically.

Typical features of a xanthogranuloma of the sellar region include cholesterol clefts, lymphoplasmacellular infiltrates, marked hemosiderin deposits, multi-nucleated foreign body giant cells around the cholesterol clefts, accumulation of macrophages and only small epithelial cell clusters [2]. These features have been found in almost all cases of sellar xanthogranuloma. It is not clear, 
however, whether the additional characteristics represent a distinct entity, given the greater number of common characteristics. Indeed, in one study, $8 \%$ of xanthogranulomas of the sellar region had histological features consistent with adenomatous craniopharyngioma, whereas 35\% (13 of 37) had squamous or columnar epithelium, but no other evidence of RCCs [2]. On the basis of these considerations and the histological findings in our patient, we speculate that our patient initially may have had RCCs or hypophysitis.

For xanthogranulomas, no typical radiological signs exist [9]. Although it is not always possible to identify the component of each signal intensity during surgery, researchers speculated in a previous report that cholesterol clefts show T1-weighted high- and T2-weighted low-signal intensities, that hemosiderin cysts containing xanthogranuloma-like fluid show T1-weighted high/iso- and T2-weighted highsignal intensities and that thick fibrosis (granulation) show both T1-weighted and T2-weighted low-signal intensities [14]. The mixed signal intensities on both T1- and T2weighted images with heterogeneous enhancement reflect their complex histologic components. The cholesterol deposits of a xanthogranuloma appear hyperintense on T1-weighted images; however, calcifications, micro- or focal hemorrhages and hemosiderin deposits contained in tumors can frequently result in heterogeneous cystic lesions and may be essential in the formation of xanthogranulomas as the trigger for granulomatous changes or as a result of these changes.

A MEDLINE English-language literature search commencing from 2000 revealed eight separate reports of cases of sellar xanthogranuloma [4-7,9,15]. MRI was performed in all eight of the reviewed cases (Table 3). Eight previous cases of sellar xanthogranuloma with MRI findings manifested hypo- and heterogeneous intensity on T2weighted imaging studies. For seven of nine reported cases (including the present case), mixed high-intensity lesions were seen on T1-weighted imaging and, generally, low or heterogeneous intensity on T2-weighted imaging.

A xanthogranuloma of the sellar region usually causes symptoms of an endocrine nature, despite favorable survival outcomes for patients with xanthogranulomas. In this case, a good outcome is defined as a socially independent life without impairment but no recovery of endocrine function. The appropriate therapeutic strategy for most cases of xanthogranuloma of the sellar region appears to be to correct the underlying endocrine problems first. Patients often need to receive long-term endocrine replacement therapy to improve their symptoms. In the eight cases of xanthogranuloma in the literature that we reviewed, no examples of recurring xanthogranuloma of the sellar region were noted, and the overall outcome for patients with this condition appeared to be favorable (Table 3). However, only three of eight patients whose intrasellar tumors were removed within 3 months of clinical onset recovered without requiring endocrine replacement therapy (Table 3). Another three patients, including the patient described in our present case report, required medical support because of mild hypopituitarism after the operation. The outcomes of the other three patients were not described (Table 3). Even if the tumor size is small, an intrasellar tumor or delayed surgical intervention probably results in unfavorable endocrine outcomes. On the contrary, despite the presence of tumors $3 \mathrm{~cm}$ or larger in diameter, suprasellar lesions appear to carry a better endocrinological prognosis if appropriate treatment is initiated as soon as possible. The increased risk of permanent pituitary dysfunction in various sellar lesions undergoing xanthogranulomatous reaction is probably related to their cause: hemorrhage, inflammation or degeneration. Therefore, surgical intervention early in the development of these changes may improve pituitary function $[5,6,15]$. This seems to suggest that surgical intervention within 3 months of clinical onset and the tumor's being in a non-intrasellar location are important factors that result in favorable postoperative pituitary function. It is possible that early surgical decompression resulted in recovery of pituitary function in cases 3,4 and 8 , but that chronic inflammation in cases 1,5 and 9 resulted in destruction and fibrosis of the pituitary as well as irreversible hormonal deficits (Table 3 ).

\section{Conclusion}

Because xanthogranulomas of the sellar region are rare, their nature and clinical course remain somewhat unclear. The seriousness of the hypopituitarism, the hyperintensity of T1-weighted MRI or hypointensity of T2-weighted MRI, and the absence of calcification should alert clinicians to the possibility that the tumor may be a xanthogranuloma. Therefore, xanthogranulomas should be included in the preoperative differential diagnosis of intrasellar tumors. Moreover, we suggest that such tumors should be treated as soon as possible, within a minimum of 3 to 4 months, especially in the case of tumors occupying the intrasellar region, to improve endocrinological outcomes, even if the tumors seem small.

\section{Consent}

Written informed consent was obtained from the patient for publication of this case report and any accompanying images. A copy of the written consent is available for review by the Editor-in-Chief of this journal.

\section{Author details}

'Division of Hematology, Endocrinology and Metabolism, Department of Internal Medicine, Faculty of Medicine, Kagawa University, 1750-1, Miki-cho, Kita-gun, Kagawa, 761-0793, Japan. ${ }^{2}$ Department of Diagnostic Pathology, Faculty of Medicine, Kagawa University, Kita-gun 761-0793, Kagawa, Japan. ${ }^{3}$ Department of Neurological Surgery, Faculty of Medicine, Kagawa University, Kagawa University, Kita-gun 761-0793, Kagawa, Japan. 


\section{Authors' contributions}

TN and KM was major contributor to the writing of the manuscript. TN, KM, $\mathrm{HI}$ and $\mathrm{TI}$ analyzed and interpreted the patient data regarding endocrinological disease. YK and RH performed the histological examination of the xanthogranuloma. NK and TT performed neurosurgery on the patient. All authors read and approved the final manuscript.

\section{Competing interests}

The authors declare that they have no competing interests.

Received: 7 September 2011 Accepted: 29 April 2012

Published: 29 April 2012

\section{References}

1. Freda PU, Post KD: Differential diagnosis of sellar masses. Endocrinol Metab Clin North Am 1999, 28:81-117.

2. Paulus W, Honegger J, Keyvani K, Fahlbusch R: Xanthogranuloma of the sellar region: a clinicopathological entity different from adamantinomatous craniopharyngioma. Acta Neuropathol 1999 97:377-382.

3. Shirataki K, Okada S, Matsumoto S: [Histopathological study of the "cholesterol granuloma reaction" in the sellar and juxta-sellar tumors] [in Japanese]. No To Shinkei 1988, 40:133-139.

4. Reithmeier T, Trost HA, Wolf S, Stölzle A, Feiden W, Lumenta CB: Xanthogranuloma of the Erdheim-Chester type within the sellar region: case report. Clin Neuropathol 2002, 21:24-28.

5. Yonezawa K, Shirataki K, Sadagami Y, Kohmura E: Panhypopituitarism induced by cholesterol granuloma in the sellar region: case report. Neurol Med Chir (Tokyo) 2003, 43:259-262.

6. Burt GM, Morey AL, Turner JJ, Pell M, Sheehy JP, Ho KK: Xanthomatous pituitary lesions: a report of two cases and review of the literature. Pituitary 2003, 6:161-168

7. Sugata S, Hirano H, Yatsushiro K, Yunoue S, Nakamura K, Arita K: Xanthogranuloma in the suprasellar region: case report. Neurol Med Chir (Tokyo) 2009, 49:124-127.

8. Zada G, Lin N, Ojerholm E, Ramkissoon S, Laws ER: Craniopharyngioma and other cystic epithelial lesions of the sellar region: a review of clinical, imaging, and histopathological relationships. Neurosurg Focus 2010, 28:E4.

9. Jung CS, Schänzer A, Hattingen E, Plate KH, Seifert V: Xanthogranuloma of the sellar region. Acta Neurochir (Wien) 2006, 148:473-477.

10. Cavallo LM, Prevedello D, Esposito F, Laws ER Jr, Dusick JR, Messina A, Jane JA Jr, Kelly DF, Cappabianca P: The role of the endoscope in the transsphenoidal management of cystic lesions of the sellar region. Neurosurg Rev 2008, 31:55-64.

11. Laws ER: Endoscopic surgery for cystic lesions of the pituitary region. Nat Clin Pract Endocrinol Metab 2008, 4:662-663.

12. Kleihues $P$, Louis DN, Scheithauer BW, Rorke LB, Reifenberger G, Burger PC, Cavenee WK: The WHO classification of tumors of the nervous system. $J$ Neuropathol Exp Neurol 2002, 61:215-229.

13. Tashiro T, Sano T, Xu B, Wakatsuki S, Kagawa N, Nishioka H, Yamada S, Kovacs K: Spectrum of different types of hypophysitis: a clinicopathologic study of hypophysitis in 31 cases. Endocr Pathol 2002, 13:183-195.

14. Nishioka H, Shibuya M, Ohtsuka K, Ikeda Y, Haraoka J: Endocrinological and MRI features of pituitary adenomas with marked xanthogranulomatous reaction. Neuroradiology 2010, 52:997-1002.

15. Liu ZH, Tzaan WC, Wu YY, Chen HC: Sellar xanthogranuloma manifesting as obstructive hydrocephalus. J Clin Neurosci 2008, 15:929-933.

doi:10.1186/1752-1947-6-119

Cite this article as: Nishiuchi et al: Xanthogranuloma of the intrasellar region presenting in pituitary dysfunction: a case report. Journal of Medical Case Reports 2012 6:119.

\section{Submit your next manuscript to BioMed Central and take full advantage of:}

- Convenient online submission

- Thorough peer review

- No space constraints or color figure charges

- Immediate publication on acceptance

- Inclusion in PubMed, CAS, Scopus and Google Scholar

- Research which is freely available for redistribution

Submit your manuscript at www.biomedcentral.com/submit
Ciomed Central 